\title{
EXPLORING THE ENERGY IMPLICATION OF URBAN DENSITY IN RESIDENTIAL BUILDINGS
}

\author{
Soufiane BOUKARTA $^{\text {a, b, } * \text {, Ewa BEREZOWSKA }}{ }^{\text {, }}$ \\ ${ }^{a}$ University of Blida1, Institute of Architecture and Urban Planning. Route de Soumâa, Blida, Algeria \\ ${ }^{\mathrm{b}}$ Ecole Polytechnique d'Architecture et d'Urbanisme (EPAU), Laboratoire Ville Urbanisme et Développement Durable (VUDD), \\ Algiers, Algeria
}

Received: 10.01.2017 / Accepted: 15.02.2017 / Revised: 15.05.2017 / Available online: 31.05.2017

DOI: $10.1515 /$ jaes-2017-0001

KEY WORDS: energy consumption, GIS, statistical approach, GHG; Density

\begin{abstract}
:
In the context of the Algerian energy policy, and through the review of the Algiers' residential building stock, this paper explores the correlation between the energy consumption of gas and electricity with urban density. Based on a holistic approach of the 57 Algiers' municipalities, the analysis is organized in two ways. Firstly, the spatial approach is conducted within a GIS implementation, carried out based on the 2013 aggregated annual energy consumption data. The cross analysis of Electricity and Gas consumption and density of population within a GIS spatial distribution approach shows effectively a strong correlation between urban density and energy consumption with a Pearson correlation of $-56 \%$ and $-65 \%$ of the Electricity and Gas consumption in the urban municipalities, respectively. Also, the household located in the suburban municipalities consume clearly more energy than the urban centered ones. Based on the electricity and gas consumption, density and carbon footprint we have clustered, within a PCA, the Algiers' municipalities into three profiles: the "thrifty", the "intermediate” and the "wasteful” profile.
\end{abstract}

\section{INTRODUCTION}

The building is widely considered as a unique study scale of the energy demand, but some key urban factors like urban density seems to play an important role in the energy load of buildings. The conclusion admitting the density as an important factor reducing the energy consumption is contrasted and still controversial in the scientific literature (Yekang, 2013). S.Salat (2011) states that for denser cities like Paris and Hong-Kong, the energy consumption of building decreases. Holden and Norland (2005) found the same conclusion in Oslo, Norway, but Steadman (1979) showed a contrary logic, stating that in higher density the energy demand due to the mobility reduces, while it increases for buildings. In the same logic, Hui (2001) and Larivière (Lariviere et al., 2009) showed the same correlation within lower density, the energy demand of buildings decreases while it increases for the mobility, and they predict that if we increase three times the density of population for a city of $1000 \mathrm{inh} / \mathrm{km}^{2}$, the electricity use would be reduced by 7 percent. On the other hand, Steemer (2003) shows a contrasted scenario basing on the building use. For the residential buildings, concluding that energy consumption is balanced between the benefits of the heat losses and the nonbenefits of reduced solar gain and daylight availability. But, for the office buildings, the increased density boosts the energy use due to the reduced availability of daylight. Also, in higher density, the potential of natural ventilation will decrease and the use of air-conditioner will increase. This positive correlation between density and energy stated by Steadman and Hui could be reported to the climate location of studied cities, which presents more HDD than CDD, where a solar gain can reduce the consumption of the energy. Less density can increase the solar gains, which matches with the results of Steadman and Hui. (Erik et al., 2016) find that the density and the height of buildings are correlated and the optimal density reducing energy use is observed at $1320 \mathrm{inh} / \mathrm{ha}$ and a building height within a range of 7-27 stories. Felix et al. (2015) find that higher gasoline prices combined with compact urban form can result in savings in both residential and transport energy use and in developing-country cities with emerging or nascent infrastructures, compact urban form, and transport planning can encourage higher population densities and subsequently avoid lock-in of high

* Corresponding author, email: sofiansasse@gmail.com 
carbon emission patterns for travel. On the same track, Pitt (2012a) based on the 2000 US census and 2005-2009 of the American community survey, finds in Blacksburg that higher urban density can reduce by up 35.5 percent the GHG emissions compared to low-urban density. In a similar study on ten Virginia metropolitan regions, Pitt (2012b) finds that the urban density can reduce down the GHG emissions approximately to 23 percent.

Furthermore, the density has been considered as a solution to reduce the energy consumption for buildings and transport in a lot of cities across the world (Newman et al., 1989; Fouchier, 1997; Camagni et al., 2002; Banister et al., 1997). The high density could also impact negatively the energy consumption of transport. Brehny (1995) highlighted the importance of the accessibility in denser cities like London. Also, Cervero (1994, 1996) stated that density has to be increased regarding public transport and the working areas, which could reduce the vehicles miles traveled. Inter alia, Brehny (1995) Grodon and Richardson (1996) had shown that high density could generate a negative effect by increasing traffic jams and pollution, because vehicles are less efficient in traffic jams than in circulation.

So, the link between transport and building energy has to be considered simultaneously (Steemers, 2003). The arguments for or against the density of cities are balanced. The Urban Task Force (1999) clearly recognizes that cities have to be well designed, more compact and better connected with a mixed-use land, in a sustainable environment adaptable to change, and well-integrated to the transport public network.
As shown above, the impact of the urban density is contrasted through different studies. Our paper highlights once more time the energy implication of urban density at the municipality scale for the department of Algiers. The conclusions of this work could help politics to determine the priorities for energy conservation measures (ECMs) (Constantinos et al., 2007) in residential buildings, in order to reduce the environmental impact of $\mathrm{CO} 2$ emissions, through the implementation of a realistic and effective action plan.

\section{CONTEXT}

Algiers, the capital of Algeria, is situated between the 30.24 and 32.55 in longitude and 2.02 and 3.25 of latitude. It has a Mediterranean climate characterized by a cool rainy winter and hot humid summer. The HDD and CDD for the 18 and $26 \mathrm{C}^{\circ}$ are respectively 125 and 555 (ONM, 2004). As an administrative department, Algiers is composed of 57 municipalities knowing a population of more than 2.9 million inhabitants in 2008 (ONS, 2008) and attracts more than 3 million persons per day (ONS, 2008). A clear movement of growth oriented mainly to the suburban municipalities characterizes its demography evolution, while the centred municipalities have a negative evolution, as shown on the Fig.1 presented below. The saturation of Algiers' center could explain this evolution, while the suburban municipalities present more virgin land potential. Algiers is the most populated metropolis in Algeria, and it has the most important part of Dwelling.

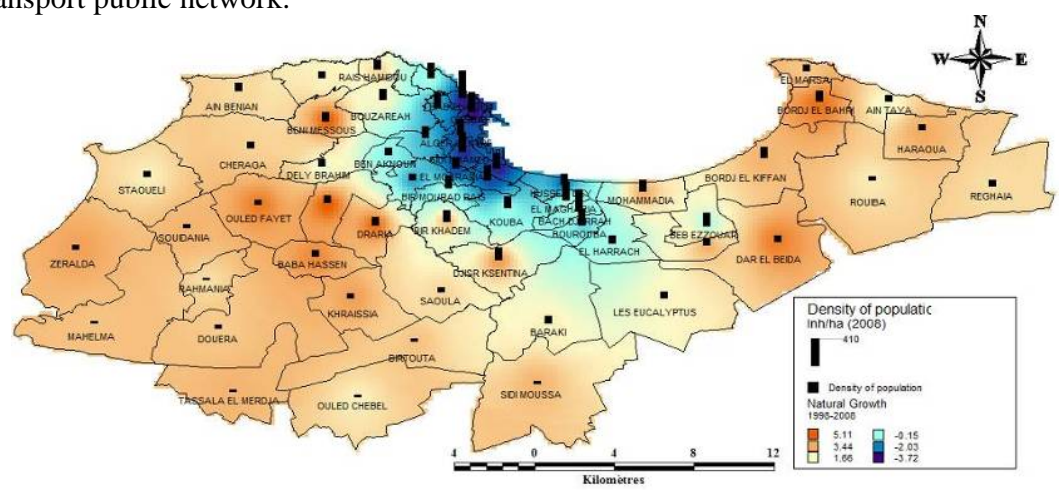

Figure 1. Density (2013) and Natural growth of the population in Algiers 1998-2008

Contrarily to the natural growth, the density still follow the general logic of distribution, meaning that the department centre of Algiers is the densest and decreases gradually going to the suburban areas, as shown on Fig. 1 above. The urban density gradient is wildly contrasted going from densest municipalities (more than $400 \mathrm{inh} / \mathrm{ha}$ ) to the least dense municipalities located in the suburban areas (less than $10 \mathrm{inh} / \mathrm{ha}$ ). 


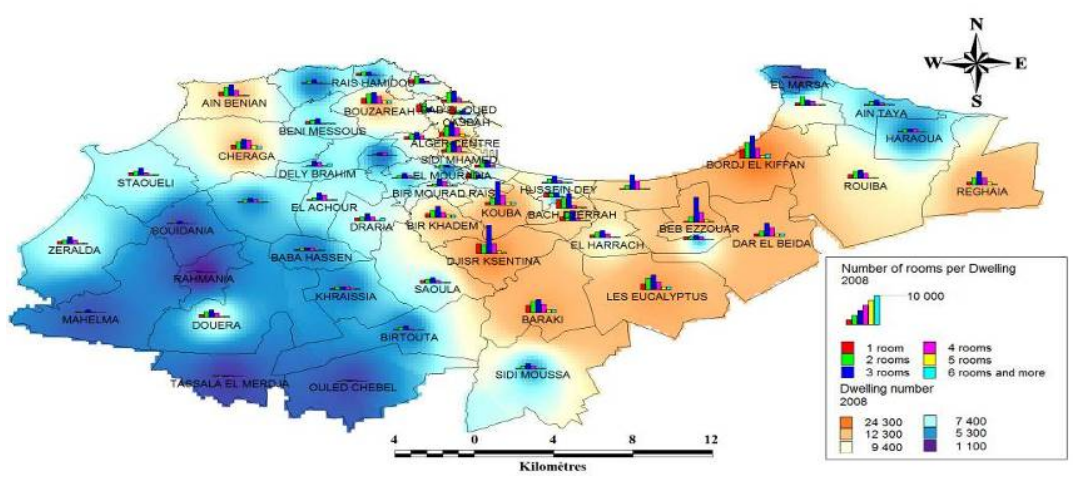

Figure 2. Distribution of dwelling number and typology per municipality (2008)

The department of Algiers is the most considered one in Algeria. Its building stock contains more than 603690 dwelling and more than 550000 household (ONS, 2008). The spatial distribution of building stock follows the general logic, understandably, the centred cities have more Dwelling (13.500$24.500)$ than the suburban ones (1.000-7.000), as shown in the figure above (fig. 2).

Also, the breakdown of dwelling size interpreted by the number of rooms per Dwelling, shows that the Dwelling with 2 rooms and one living room (Fig. 3) is the typology more widespread in the department of Algiers (figure 4 and 5 above). The mean number of rooms per Dwelling is the highest (3.214.95) in the central municipalities, and the weakest mean is observed in the second crown of the suburban cities, with a range of (2.12-2.68).

\section{MATERIALS AND METHOD}

In our Algerian case context, the scale of municipality is mostly the appropriate one due to its representation as a clear administrative area (European Commission, 2011) and the politics' decision and assessment are implemented at the local scale. Secondly, we choose the top-down, statistical and GISbased approach because the purpose of this paper is analysing realistic data. The proclaimed choice is shored up by the fact that the Data, for energy exists at the municipality scale. Furthermore, a bottom-up approach based on sampling could be weightier if we take into consideration the 57 municipalities of Algiers' department. Finally, our paper focuses on exploring the correlation between the energy consumption of gas and electricity with the urban density.

At this stage, we have used the Algiers 2013 yearly energy enduse of the residential stock of 57 of the department's municipalities acquired from Sonelgaz, the firm invoicing the energy consumption in Algeria. The energy end-use concerns Gaz and Electricity for households. In the same Data, we have got the number of households per municipality. And from the ONS data (2013) we have acquired the 2013 population Data. By implementing this Data in a GIS, we firstly analyzed the breakdown of the energy consumption and Greenhouse gas emission (GHG) within the department of Algiers, and we observe whether a correlation between the energy consumption according to a spatial logic exists. The energy end-use regarding Electricity and Gas is always presented in three ways: the sum per city, the mean energy consumption per household and per city, and per inhabitant and per city.

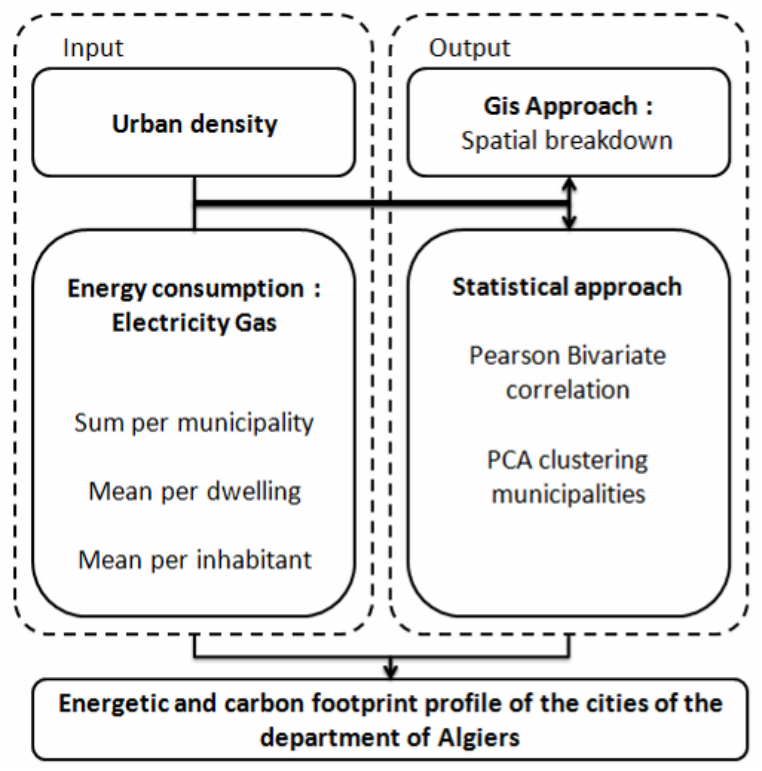

Figure 3. Method framework

The statistical approach is conducted to confirm our observation and to quantify the impact of the density on the energy consumption of both Electricity and Gas. A Pearson bivariate correlation is used to assess the density impact and a Principal component Analysis (PCA) is performed to cluster municipalities considering their energy consumption, carbon footprint and the urban density as well.

\section{RESULTS}

\subsection{Results regarding Gas consumption}

In the Gas consumption per municipality analysis (Fig. 4 below), the rate of population per municipality seems to be strongly correlated to the Gas consumption with a Pearson coefficient $\left(\mathrm{R}^{2}\right)$ of $79.3 \%$. Within populated cities, the gas consumption will increase. Whereas, at this scale, the density correlated to the sum of gas consumption per city explains weakly the energy end-use distribution $\left(R^{2}=-4.9 \%\right)$. 


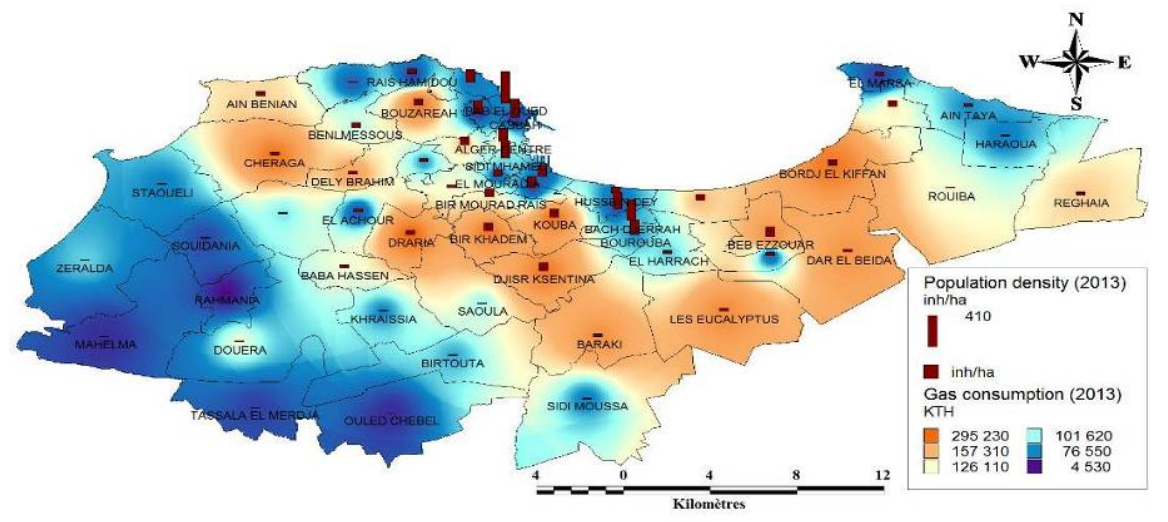

Figure 4. Gas consumption and Density per municipality (2013)

The figure 5 below representing the breakdown of the density and the mean gas consumption per Dwelling and per municipality reveals a strong correlation between the urban density (inhabitants/ha) per municipality and the consumption of the Gas per Dwelling. The correlation coefficient is negative, more than $-65 \%$, which means that within higher density, the Gas energy demand decreases. The mean consumption per Dwelling is $16698,21 \mathrm{Kth} /$ year and the standard deviation is

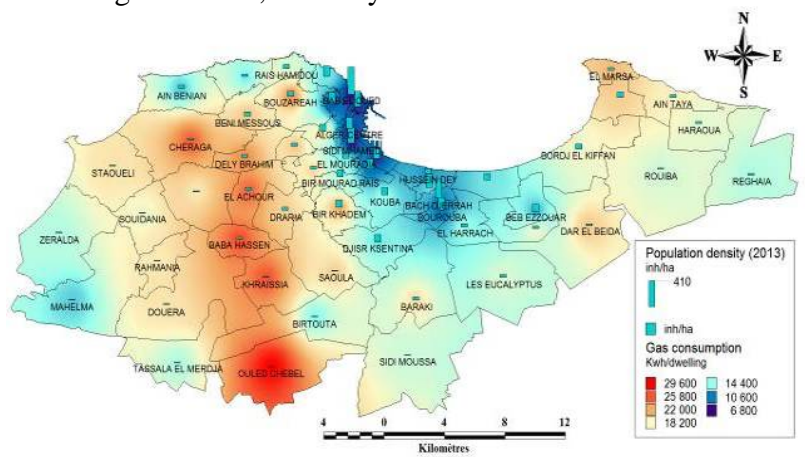

Figure 5. Density per municipality and mean Gas consumption per Dwelling

The distribution of the Gas energy end-use per inhabitant and the density of population presented on the figure 6 above reveals that the density explains the gas consumption by $19.43 \%$. There is no evident correlation between these two factors. The mean Gas consumption is about $2.075 \mathrm{Kth} / \mathrm{inh} / \mathrm{y}$, the maximum is observed in the suburban municipality of Rahmania with a density of $9.52 \mathrm{inh} / \mathrm{ha}$, and the minimum is observed also at the suburban municipality of Draria with
5192,21 Kth, with the minimum recorded at the municipality of Bab El Oued (6838,93 Kth/year/ Dwelling) with a density of more than 409 inh/ha, while the higher gas consumption is observed at the suburban municipality of Ouled Chebel, with a consumption of 29564,6 Kth/y/ Dwelling and a density of 7.69 inh/ha.

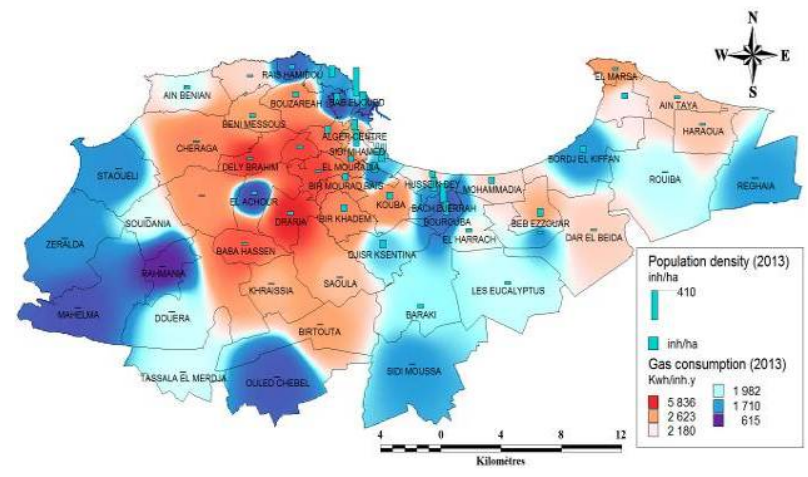

Figure 6. Gas consumption per inhabitant per year

5.03Kth/inh/y and a density of $55 \mathrm{inh} / \mathrm{ha}$. Seemingly, the density has no major role on the Gas consumption at this scale.

\subsection{Results regarding Electricity Consumption:}

The figure 7 below of Electricity end-use for the residential stock per municipality shows three crescents distribution. The middle crescent (the red one) represents clearly a lack of correlation between the studied factors.

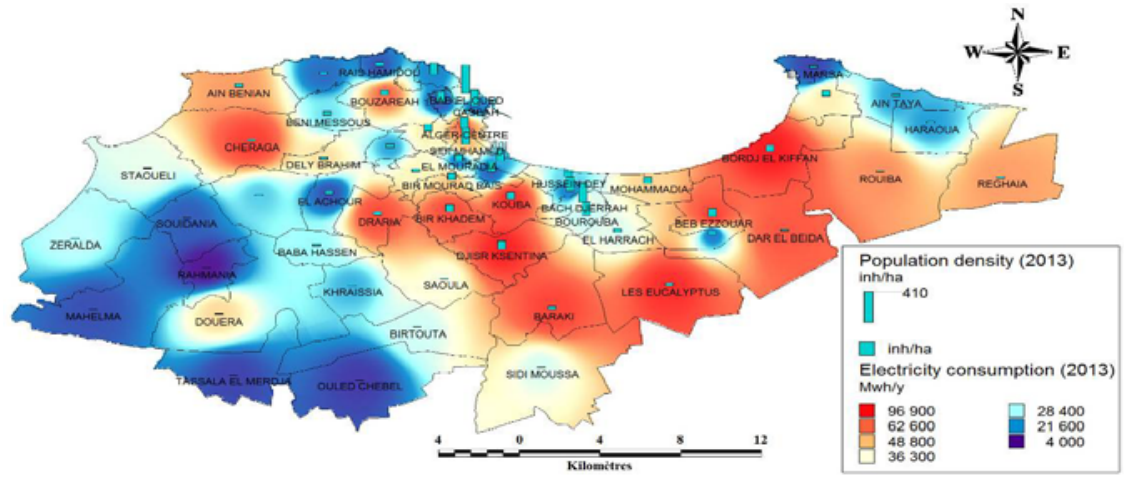

Figure 7. Electricity consumption and Density (2013) 
This second (red) urban crown of Algiers is less dense than the center, but its energy load is the most important, with a consumption contained between 63.000 and more than 96.000 $\mathrm{Mwh} / \mathrm{city} / \mathrm{y}$. The crescent of the densest central municipalities shows an Electricity consumption between 27.500 and less than $5.000 \mathrm{Mwh} / \mathrm{city} / \mathrm{y}$. Bab El Oued is the municipality which consumes less Electricity energy and its density of population is the most noticeable with more than $400 \mathrm{inh} / \mathrm{ha}$ (2013). The third crescent represents the second range of suburban municipalities, more rural than urban. We acknowledge a decreasing of the electricity consumption, instead of increasing, with less density and this is due to the calculation method of the urban density, which considers the entire municipality area, gathering the urbanized and the non-urbanized one. However, this reversed logic can be brought back if we consider only the Morphological Urban Area (MUA) which depicts the continuity

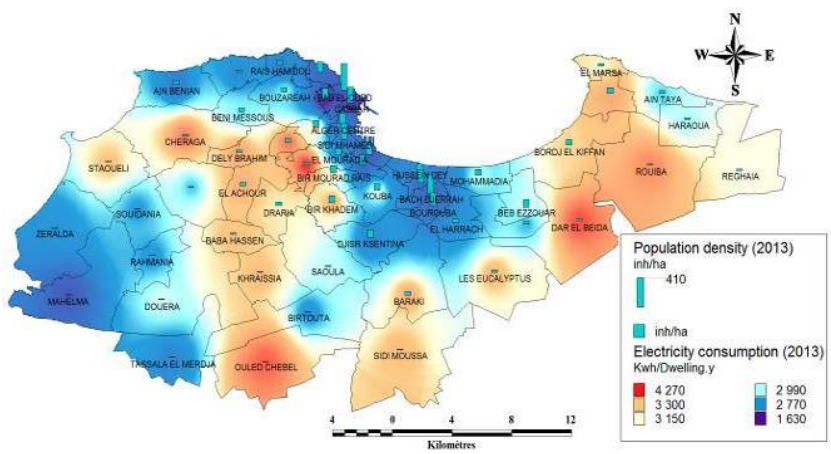

Figure 8. Electricity consumption per Dwelling and density (2013)

The Electricity consumption per inhabitant seems not to be correlated to the density. The electricity consumption per inhabitant varies between 221 to 1195 kwh/inh.y. Even if statistically, the breakdown of the electricity consumption is not clearly correlated to the density, we can notify on the map below that in the centre of the department, the municipalities are denser and the electricity consumption per inhabitant is medium to weak. While in the suburban municipalities, like Bordj El Kiffan and Ouled Chebel, the electricity consumption per inhabitant is more important. of the built-up space with a defined level of density (European Commission, 2011).

The Electricity energy consumption distributed per Dwelling (figure 8) explains clearly a reversed correlation between the density and the electricity consumption. The correlation is negative and surpasses $-56 \%$. Within higher densities, the electricity consumption per Dwelling decreases. Knowing that, this correlation is not representative when we focus our observation on the suburban municipalities, which are less dense. The calculation method of the urban density and the compactness of buildings could explain the electricity consumption decrease. The same conclusion was given in the Belgium context (Manoj et al., 2013). Detached houses consume more energy than attached ones, which have more sharing parts.

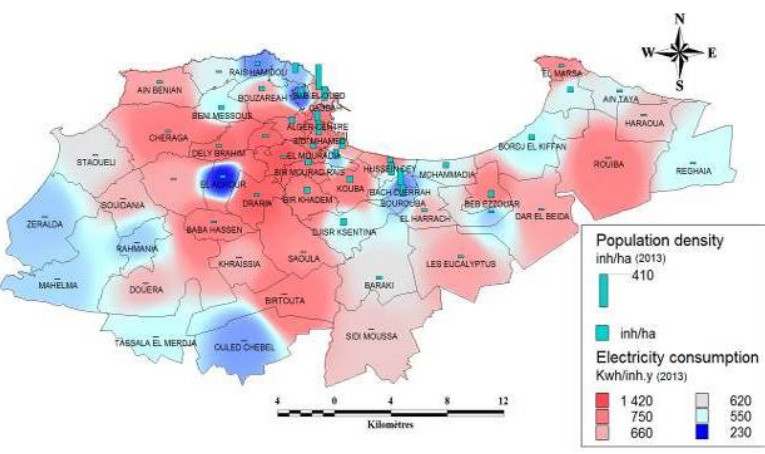

Figure 9. Electricity consumption per inhabitant and density (2013)

The Pearson correlation (table 1) at the three scales shows that: (i) the density has an important impact on the gas consumption only at the Dwelling scale, while (ii) the population number has an important impact on the Gas energy consumption at the municipality scale. The most populated municipalities consume more Gas energy and the households located in the densest municipalities consume less energy.

Table 1.Gas consumption correlation with density and population

\begin{tabular}{|c|c|c|c|c|c|c|c|}
\hline \multirow{2}{*}{\multicolumn{2}{|c|}{ Energy consumption }} & \multicolumn{3}{|c|}{ Gas consumption per : } & \multicolumn{3}{|c|}{ Electricity consumption per : } \\
\hline & & \multirow{2}{*}{$\begin{array}{r}\text { municipality } \\
-.049 \\
\end{array}$} & \multirow{2}{*}{$\begin{array}{c}\text { Dwelling } \\
-, 657^{* *}\end{array}$} & \multirow{2}{*}{$\begin{array}{r}\text { Inhabitant } \\
-.194\end{array}$} & \multirow{2}{*}{$\begin{array}{r}\text { municipality } \\
.038\end{array}$} & \multirow{2}{*}{$\begin{array}{r}\text { Dwelling } \\
-, 561^{* *}\end{array}$} & \multirow{2}{*}{$\begin{array}{r}\text { inhabitant } \\
-.054\end{array}$} \\
\hline densit_pop13 & Pearson Correlation & & & & & & \\
\hline & Sig. (2-tailed) & .716 & .000 & .148 & .777 & .000 & .692 \\
\hline & $\mathrm{N}$ & 57 & 57 & 57 & 57 & 57 & 57 \\
\hline \multirow[t]{3}{*}{ pop_2013 } & Pearson Correlation &, $793^{* *}$ & -.006 & -.091 & $\mathbf{8 8 0}^{* *}$ & .193 & -.103 \\
\hline & Sig. (2-tailed) & .000 & .966 & .503 & .000 & .151 & .445 \\
\hline & $\mathrm{N}$ & 57 & 57 & 57 & 57 & 57 & 57 \\
\hline
\end{tabular}

** Significant at 0.01

* Sig at 0.05 


\subsection{Greenhouse Gases emission (GHG)}

\subsubsection{GHG emitted from Gas consumption}

According to the referential norms of GHG reported by the International Energy Agency IEA (2008), which gives the international emission factors of greenhouse gases (ADEME, 2010), we have acquired the emission factors for Gas and Electricity for Algeria. For each $1 \mathrm{kwh}$ of consumed Electricity, $188 \mathrm{~g}$ equivalent Carbon is emitted and $206 \mathrm{~g}$ per $1 \mathrm{kwh}$ for the Gas energy. It is clear that the GHG are directly correlated with the energy consumption and nature. Based on given emission factors, we performed a GIS in order to obtain the spatial distribution of the GHG per city for the department of Algiers. It is important to highlight that the GHG emitted from the Gas energy consumption in Algiers are five times more important than those due to the Electricity consumption.

According to the map below, presenting the GHG due to the Gas consumption, we can easily explain the distribution of the GHG according to the density. In higher density, the GHG decreases to the minimum with $1100 \mathrm{TeCO}^{2} / \mathrm{y}$ per municipality, as in Algiers-center, Mohammadia, Bab El Oued and La Casbah, while it tends to increase considerably in the suburban municipalities, as BirKhadem, Cheraga, Draria, with an emission rising up to $69000 \mathrm{TeCO}^{2} / \mathrm{y}$ (See figure 10).

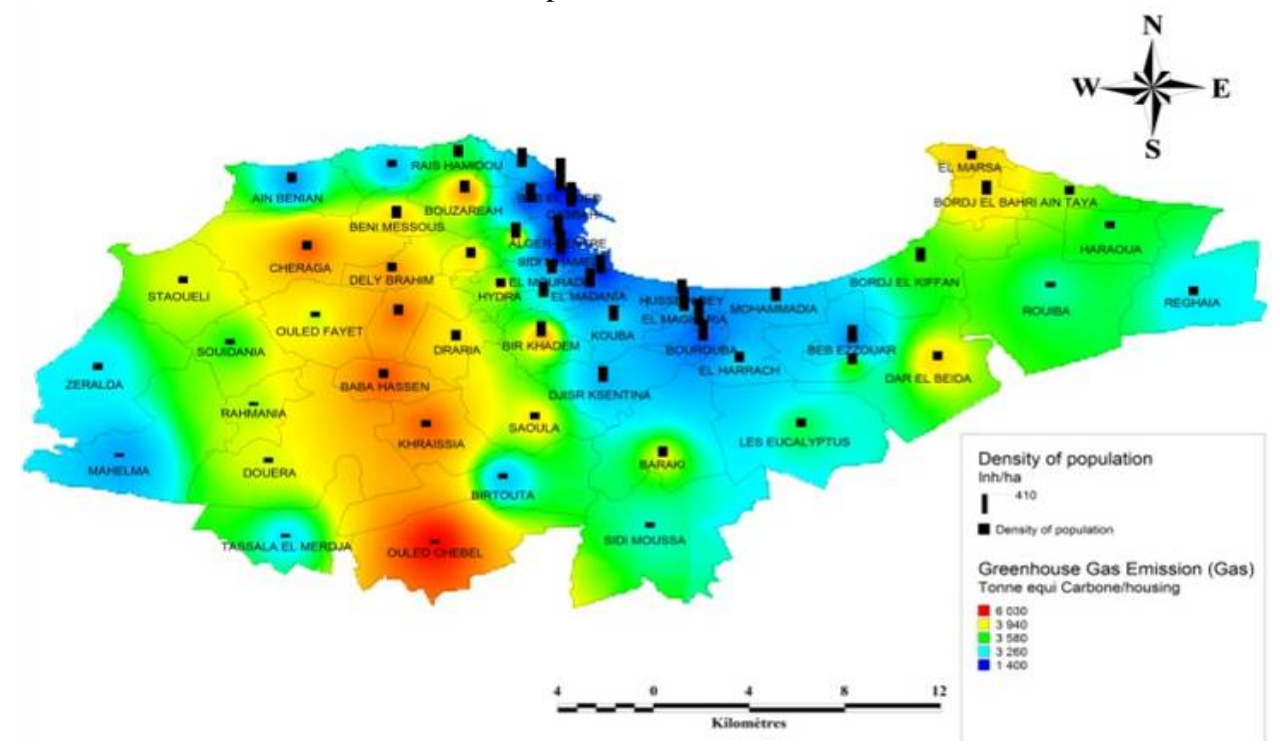

Figure 10. Average GHG per Dwelling emitted from the Gas consumption

Also, for the west suburban municipalities as Zeralda, Mahelma, Ouled Chebel, we observe a weak GHG rate even if the density is lower. The explanation of this reversed correlation could be reported to same arguments presented above, meaning that the calculation method of the density considers the entire area of the municipality containing suburban (built-up area) and rural zone (unbuilt area). If we consider only the MUA, the density will increase and the lower GHG remains correlated to higher density.

\subsubsection{GHG emitted from the electricity consumption}

The GHG emission due to the Electricity consumption seems to follow the same logic, as the density has a clear negative impact and reduces the GHG. The GHG resulting from the Electricity consumption is lesser than the GHG of the Gas. This could be explained by the important use of the Gas in household activities as heating and cooking.

The GHG per Dwelling per year is clearly correlated to the density; the densest municipalities like Bab El Oued emit the minimum GHG with 306 and increase up to $800 \mathrm{Tec} /$ Dwelling.year for the less dense ones like Oulad Chebel.

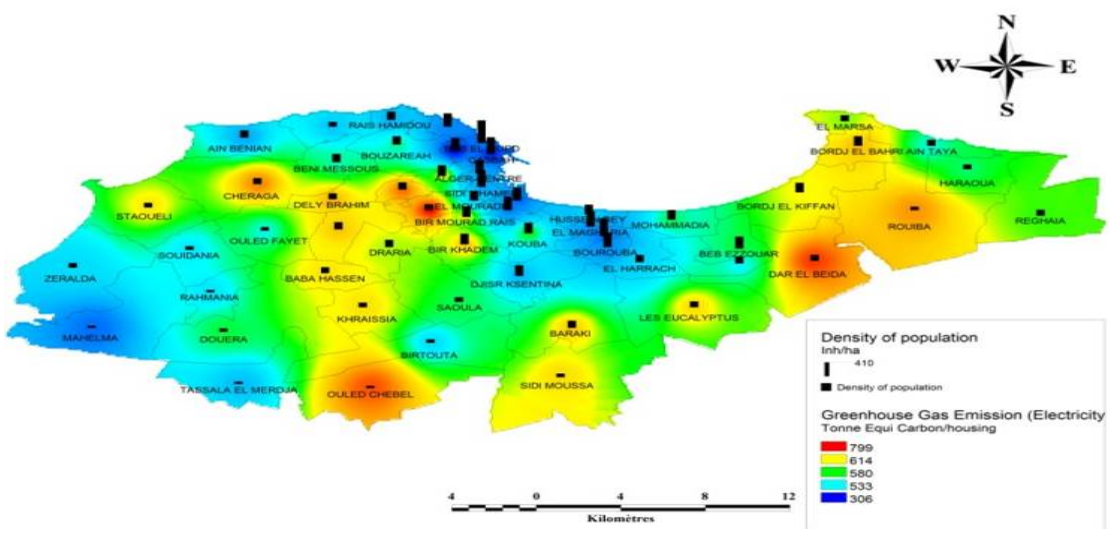

Figure 11. Mean GHG per dwelling per year emitted from the electricity consumption (2013) 


\subsection{Algiers' energetic profile}

We have clustered the 57Algiers' municipalities in three profiles, based on the Principal Component Analysis (PCA) which considers as discriminant the Gas and Electricity consumption for all these municipalities and some other key factors, like population and its density and the Greenhouse gases emission.

Diagramme de composantes dans l'espace après rotation

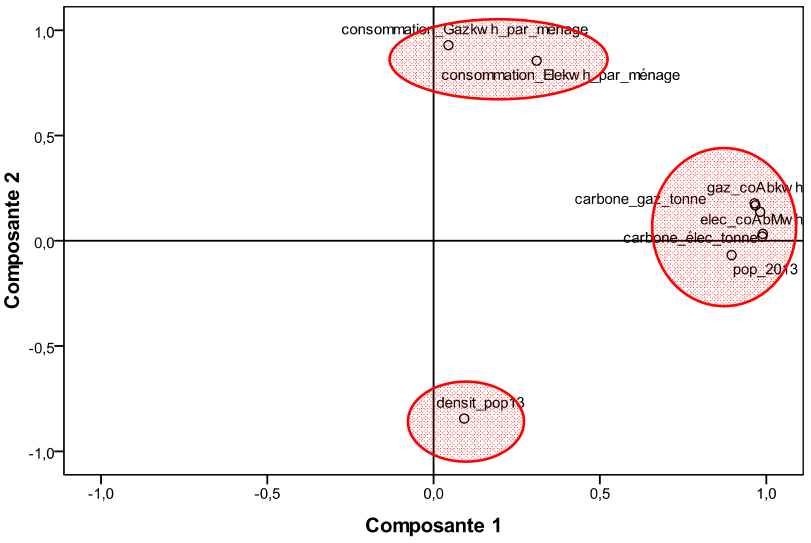

Figure 12. Factorial analysis considering Density, Energy consumption and GHG emission

The quality of the representation is above $89 \%$ on two axes. Through this PCA, the Density of population, Gas and Electricity consumption per Dwelling are represented in an opposite way, which means that the dense municipalities consume less Electricity and Gas energy per dwelling, while the consumption of both Electricity and Gas, population number and GHG per municipality as well, are presented on the same $\mathrm{X}$ axe which can be interpreted by a positive correlation. The most populated municipalities consume more energy and emit more GHG.

The PCA presented below shows three profiles. We note the thrifty profile; standard and the wasteful one (see Fig. 13). (i) Thrifty profile: 11 municipalities represented by the green color. They are located in the urban area. This profile gathers denser cities, which consume less energy for both Electricity and Gas per Dwelling; e.g., Bab El Oued constitutes the less energy consumer from all the 57 cities, as Casbah comes in the second range. The sum of consumption per municipality is average. In this class, Algiers-center is considered the top consumer and Casbah is the lesser one at the municipality scale. Their GHG is the weakest per Dwelling and average if we consider the GHG at the municipality scale as well as the centered municipalities are the most populated.

(ii) Intermediate profile: 34 cities are represented in orange color. It contains the suburban municipalities, which have the most important consumption per Dwelling for both Electricity and Gas, with the weakest density for all the department of Algiers. Ouled Chebel is the lesser dense city with less than 10 inh/ha of density, but its consumption of both Gas and Electricity is highly important (29.000 kwh/ Dwelling.y), while the minimum is observed in Bab El Oued municipality, with $6800 \mathrm{kth} / \mathrm{Dwelling}$ year. Also, the difference in terms of Electricity consumption is very important, the minimum is obtained in class 1 for Oued Koriche (1626.46 kwh/
Dwelling.y) and the maximum is observed in class 2 for Hydra (4278.68 kwh/ Dwelling.y). At the city scale, this class has an average Energy consumption and GHG.

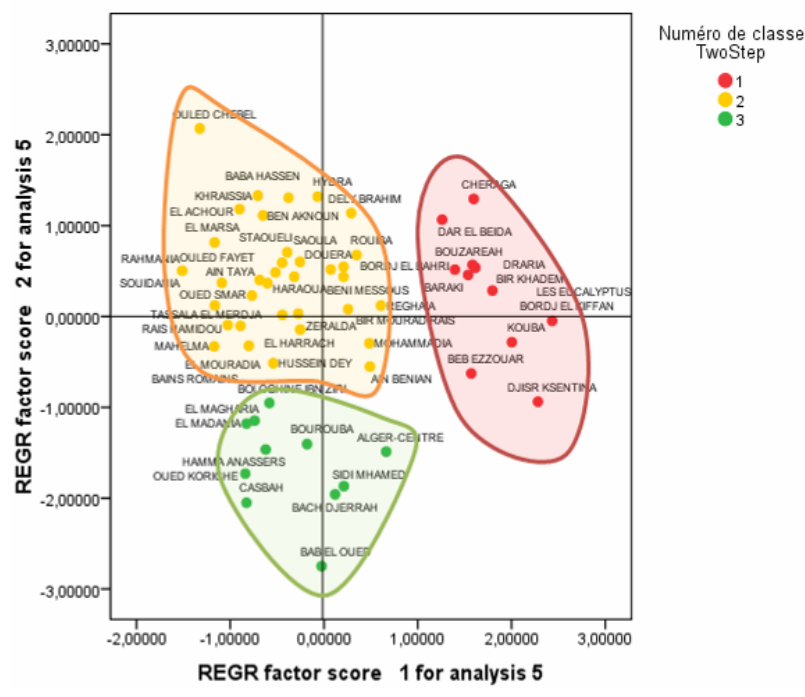

Figure 13. Global Energy consumption profile of the 57 municipalities of Algiers

(iii) Wasteful profile: represented in red color and contains 12 suburban municipalities. Both the Energy consumption per Dwelling and per municipality are the highest in the entire department of Algiers.

\section{CONCLUSION: DENSITY, GAS AND ELECTRICITY CONSUMPTION, WHAT RELATIONSHIP?}

The analysis presented above shows that the energy consumption of both electricity and Gas is correlated to the Algiers' urban density. This correlation is clear at the Dwelling scale with $-56 \%$ and $-65 \%$ respectively for Electricity and Gas. The sum of consumption at the scale of the city is strongly correlated to the population number per city with $88 \%$ and 79.3\% for Electricity and Gas. Our paper claims a positive role of the urban density in reducing energy consumption and GHG in residential building within GIS and Statistical-based approach.

\section{REFERENCES}

ADEME, 2010, Bilan Carbone ${ }^{\circledR}$, Entreprise et collectivités, Guide des facteurs d'émission (Emission factors guide), V 6.1, Chapter 2.

Banister, D., Watson, S. and Wood C. (1997), Sustainable Cities, Transport, Energy and Urban Form, Environment and Planning B: Planning and Design, Vol. 24, pp. 125- 143.

Breheny.M, (1995), The compact city and transport energy consumption, Transactions of. The Institute of British Geographers, New Series, Vol. 20, No. 1, pp. 81-101. 
Camagni Roberto, Paolo Rigamonti, Maria Cristina Gibelli, (2002), "Forme urbaine et mobilité: les coûts collectifs des différents types d'extension urbaine dans l'agglomération milanaise" (Urban form and mobility: the collective costs of the different types of urban extension in the Milanese agglomeration), Revue d'économie régionale et urbaine, $\mathrm{n}^{\circ} 1$, pp. 105-140.

Cervero R. (1994), Transit-based housing in California: evidence on ridership impacts. PO/. 1, 174-183.

Cervero, R. (1996), California's Transit Village Movement. Journal of Public Transportation 1, 1: 103-130.

C.M. Hui, (2001), Low energy building design in high density urban cities. Renewable Energy 24, pp. 627-640.

Constantinos A. Balarasa, Athina G. Gagliaa, Elena Georgopouloub, Sevastianos Mirasgedisb, Yiannis Sarafidisb, Dimitris P. Lalas (2007), European residential buildings and empirical assessment of the Hellenic building stock, energy consumption, emissions and potential energy savings. Building and Environment, 42, pp. 1298-1314.

Eirik Rescha , Rolf André Bohnea, Trond Kvamsdalb , Jardar Lohnea (2016), Impact of urban density and building height on energy use in cities, in SBE16 Energy Procedia 96 ( 2016 ), pp. $800-814$.

European Commission, (2011) Regional Policy Cities, of tomorrow, challenges, visions, ways forward, Luxembourg PO, 112 p., ISBN: 978-92-79-21307-6.

Felix Creutzig, Giovanni Baiocchi, Robert Bierkandt, PeterPaul Pichler, Karen C. Seto (2015), Global typology of urban energy use and potentials for an urbanization mitigation wedge, in Proc Natl Acad Sci U S A, vol. 112 no. 20, 6283-6288, doi: 10.1073/pnas.1315545112.

FOUCHIER V. (1997), Des fortes densités urbaines. Les villes nouvelles dans l'espace métropolitain (High urban densities. New cities in the metropolitan area), Phd thesis, University of Paris VIII.

Gordon, P., and H.W. Richardson (1996), Beyond polycentricity: the dispersed metropolis, Los Angeles, 19701990, Journal of American Planning Association, 62 (3).

Holden, E., and I. T. Norland (2005). Three Challenges for the Compact City as a Sustainable Urban Form: Household consumption of Energy and Transport in Eight Residential Areas in the Greater Oslo Region. Urban Studies 42 (12): 2145.

Isabelle Lariviere, Gaetan Lafrance (1999), Modelling the electricity consumption of cities: effect of urban density, Energy Economics 21 53-66.

K. Steemers (2003), Energy and the city: density, buildings and transport, Energy and Buildings (35) 3-14.

Lariviere, Isabelle, and Gae"tan Lafrance (1999). Modelling the Electricity Consumption of Cities: Effect of Urban Density. Energy economics 21 (1): 53-66.
Manoj Kumar Singh a,n, SadhanMahapatra, Jacques Teller (2013), An analysis on energy efficiency initiatives in the building stock of Liege,Belgium, Energy Policy, 62, pp. 729741.

Newman, P. W. G. and J. R. Kenworthy (1989). Cities and Automobile Dependence: An International Sourcebook. Aldershot, UK: Gower.

ONM (2004), office national de météorologie, weather Data of Algiers (1994-2004), Algeria.

ONS (2008), office national de statistiques, Census data 2008, Algeria.

ONS (2013), office national de statistiques, population Data, Algeria.

Pitt, Damian. (2012a), Assessing Energy Use and Greenhouse Gas Emission Savings from Compact Housing: A Small-town Case Study. Local Environment: The International Journal of Justice and Sustainability. doi:10.1080/13549839.2012.748724.

Pitt, Damian. (2012b). Evaluating the Greenhouse Gas Reduction Benefits of Compact Housing Development. Journal of Environmental Planning and Management. 56 (4): 588-606.

Serge Salat (2011), Les villes et les formes urbaines: sur l'urbanisme durable (Cities and urban forms: on sustainable urban planning), éd Hermann, France.

Steadman, P. (1979). Energy and patterns of land use. In: Energy conservation through building design. Ed. Watson, D. McGraw-Hill, New York, pp. 246-260.

The Urban Task Force (1999), Towards an Urban Renaissance, E\&FN Spon, London, June.

Yekang Ko (2013), Urban Form and Residential Energy Use: A Review of Design Principles and Research Findings, Journal of Planning Literature, 28(4), pp. 327-351, DOI: $10.1177 / 0885412213491499$. 